\title{
Relación entre Iglesia y Arte durante el Virreinato del Perú: Aproximación
}

\author{
MARTHA BARRIGA TELLO
}

La justificación dada por la corona española para la ocupación y sujeción de los pueblos encontrados por los viajeros españoles en América fue el incorporarlos a la religión cristiano-romana. Para darle validez a esta posición, el monarca demostró temprana preocupación en construir templos cristianos inmediatamente sus súbditos se establecían en estas tierras.

En el Perú, esta inquietud fue manifiesta en los primeros españoles cuando fundaban una ciudad Unos de los solares asignados en lugar preminente era el de la iglesia, la que frecuentemente presidía la plaza mayor. Estas sin embargo fueron entonces sencillas y provisionales. Respondían sólo a la necesidad de contar rápidamente con un local adecuado parbeli cuttocenda Verdadera relación de la conquista del Perú y la provindiardel POazco elläinada Nrieva Castilla (1534) que escribiera el que fue Secretario de Pizarro, Francisco de Xerez se menciona que éste, "mandó hacer en la plaza de Caxamalca una iglesia donde se celebrase el santísimo Sacramento de la misa, y mandó derribar la cerca de la plaza, porque era baja, y fue hecha de tapias de altura de dos estadios, de largura de quinientos y cincuenta pasos". (1968-1; 238)

Una referencia posterior la hace Pedro de Cieza de León en la Primera parte de la Crónica del Perú (1550), "La ciudad de San Miguel fue la primera que en este reino se fundó por el marqués don Francisco Pizarro, y donde se hizo el primer templo a la honra de nuestro Señor". (1962, Cap. LVII). Escasos los datos y poco el interés que presentaban entoces. Inicialmente tampoco fueron muchas las espectativas respecto a ellos, pues aunque el arzobispo de Lima había considerado 
que la obra catedralicia de su ciudad era "muy fuerte, de suerte que queda con autoridad y honra que conviene para el culto divino y a mucho contento de la dicha ciudad". Bernabé Cobo responde que "debiera ser para aquellos tiempos, tan cortos de ánimo como esta ciudad lo era de vecinos; que a la verdad los que la alcanzamos la juzgamos por muy pequeña y humilde, con su coro alto muy pequeño, y el día de hoy fuera de menos lustre y hermosura que cualquiera de las parroquias de la ciudad, porque su edificio era de adobes, cubierto de esteras y en nada representaba la dignidad de catedral metropolitana". (Historia de la fundación de Lima, Libro $2^{\circ}$. Cap. II)

Se explica el comentario porque los edificios religiosos se levantaban generalmente con materiales propios de cada región, posteriormente se importarían los más adecuados allí donde no se disponía de los necesarios. Para la fábrica se contó con la mano de obra indígena, participación que estuvo regulada por disposiciones estrictas de la Corona. Obligatoriamente los habitantes de la ciudad debían enviar indios de las encomiendas a su cargo a colaborar en las obras. Por otra parte el templo y todos loselementos que lo conformaban al interior, como esculturas y pinturas, constituían los medios de acción de la agresiva labor evangelizadora de los misioneros y clérigos. En razón de ello la preocupaciónzy/elijnterés que ponian en él en su conjunto contribuyó al engrandecimiento del mismo. Las disposiciones reales estipulaban que esta tarea estaba bajo responsabilidad de los arzobispos, obispos, prelados y diocesanos quienes debían guardar, bajo responsabilidad, las normas que al efecto se habían dictado. Las Audiencias Reales quedaron facultadas para ejercer su autoridad en lo conducente a consolidar su cumplimiento: "Encargamos al prelado que con todo cuidado y diligencia atienda a dar orden como las dichas iglesias se edifiquen con toda brevedad, usando de todos los medios que fuere necesarios para el culto... Todos los Arzobispos, obispos y prelados diocesanos guarden y hagan guardar y cumplir lo dispuesto en las erecciones de su iglesia, y así no lo hicieran, las nuestras audiencias reales de oficio o a pedimento de parte las hagan guardar..." (1563: Estatuto de la organización de las Iglesias de Indias. En: Arragaray, Lucas, 1920, Apéndice 2) El monarca continuamente exhortaba a sus delegados lo mantuvieran al tanto de todo lo referente a las fábricas, de 
sus necesidades fundamentales y sobre todo de la correcta distribución del dinero empleado en ellas. Una carta al rey del virrey del Perú, don Luis de Velasco del 5 de mayo de 1600 nos brinda una interesante confirmación al respecto. Entre otros puntos relacionados con asuntos eclesiásticos dice: "La obra de la Catedral se va prosiguiendo conforme a la traza que escribí a V. M. se había elegido para que sea más fuerte y segura y menos costosa y se acabe más presto y he ordenado al obrero mayor envíe en esta flota la planta para que siendo V. M. servido la vean oficiales se tome su parecer". (En: Lissón Chávez, Emilio, 1946, Vol. IV, N¹9).

El Estatuto de 1563 justificaba la preocupación del virrey en cuanto específicamente se señalaba: "Y antes de que la iglesia se comience a edificar se haga perfectamente la traza y condición della y se señale la planta y toda la montea con su pitipié [escala actual], y describan las condiciones y se tantee lo que podrá costar la labor de la iglesia y el tiempo que tardaría en labrarse con la dote y hacienda que tiene la iglesia para se labrar, y así se levante la obra en proporción que se pueda fácilmente acabar... de piedra donde hubiere... prosiguiendo el edificio suntuosamente y como convenga". (Loc. cit.)

Del mismo modo, la Iglesia dispuso la fiscalización por parte de sus miembros, de toda obra de pintura y escultura que se realizase en los territorios americanos con la facultad de reformarlas o retirarlas si encontraban algunas deformes 0 indecentes. Basaban esta determinación en la importancia reconocida de las representaciones como medio de evangelización de quienes no podían acceder a la lectura. Interés constante, por otra parte, desde el Primer Concilio Limense en 1551 y sobre todo en el Segundo, cuando ya habían llegado a Lima las constituciones del Concilio de Trento, muy específico en este particular.

En base a esta información, se comprende que la Iglesia, a partir de los primeros años de colonización, se preocupase por cumplir a cabalidad su cometido.

Si consideramos a los artistas y artesanos que trabajaron en Lima durante esta etapa, apreciaremos que entre ellos se presentan varias formas de acceder al oficio. James Lockhardt (1982) estima que la cifra de artesanos en el Perú hacia 1560 ascendería a 2,500, en una 110 
proporción de 1 por cada 10 habitantes, suma que aumentó considerablemente a partir de esa fecha. La necesidad de levantar las ciudades, la facilidad con que los primeros colonizadores-conquistadores se hicieron de grandes fortunas que deseaban ver reflejada en sus bienes muebles e inmuebles, hizo que llegaran a convertirse en artesanos hombres de las más variadas procedencias. Se hacen artesanos:

a.-Los que siendo soldados adoptan un oficio artístico para ganarse el sustento, toda vez que su posición no era relevante en la hueste conquistadora.

b.- Los que siendo artistas se alistan como soldados para facilitarse el permiso de traslado desde Europa. de origen.

c.- Los que llegan siendo artistas sin mucho porvenir en su lugar

d.-Los que siendo artistas reçonocidos arriban en el séquito de una autoridad o son convocados para tareas específicas.

e.-Los que forman parte de una Orden religiosa.

f.- Los que siendo mestizos, negros o naturales de la tierra aprenden un oficio con alguno de los mencionados grupos.

Cualquiera fuera la vía de acceso, todos dependían para la elaboración de sus obras; diregta o indirectamente ${ }_{5}$ de la autoridad eclesiástica. Los unos porque era ésta la entidad contratante o aquella a la cual pertenecían. Los otros, porque la fiscalización que la Iglesia ejercía se extendía al ámbito de la espiritualidad seglar en toda ocasión en que una producción de arte tratara un tema de su incumbencia. Ser "pastor de almas" implicaba responsabilidades amplias y respuestas severas.

Una muestra de todo ello se encuentra en la manera cómo las autoridades de las diversas Ordenes asumían, muchas veces totalmente, la responsabilidad de la ejecución de obras necesarias para el culto. Así fray Tomás de San Martín, padre dominico que fue Provincial del convento de su Orden en Lima entre 1540 y 1552 , época difícil e incierta en muchos aspectos. Fray Tomás salía cada mañana muy temprano desde su convento hasta la calera que le había sido donada a su congregación en la hacienda Limatambo, un tanto lejos de la ciudad. Allí permanecía sin comer controlando los trabajos, inspeccionando 
la extracción del material y la factura de los ladrillos que posteriormente se preocupaba fueran colocados correctamente en la fábrica de su iglesia y convento. A este celo se debió que adelantara la fábrica en corto tiempo. (Reginaldo de Lizárraga, O.P. 1968, I, XXIII).

Igualmente frailes de otras Ordenes religiosas emprendían tareas relacionadas a la edificación y adorno de sus dependencias. Algunos participaban activamente como artistas. Tal el caso de los jesuitas Jerónimo Ruiz del Portillo, Juan Ruiz, Bernardo Bitti y Alonso Pérez; los dominicos Juan García y Diego Maroto, Salvador de Rivera, todos reconocidos como excelentes maestros en diferentes actividades artísticas. En tal condición viajaban por el Virreinato, cumpliendo igualmente con los pedidos de las autoridades civiles, quienes reconociendo sus cualidades, solicitaban asesoramiento para las diversas obras emprendidas en las ciudades. No extrañaba, entonces, que un fraile impartiera sus conocimientos a aprendices que acudían a los conventos, instruyéndolos al pie de la obra. Muchas veces él mismo, con un poco de habilidad y basándose en los numerosos textos impresos y manuscritos, que por entonces circulaban en las colonias, referidos a las técnicas de manufactura de diversas artes (Serlio, Vignola, Vitruvio, entre otros de tradición medieval que formaban parte de las bibliotecas conventuales europeas $\chi$ americanas habia accedido al oficio impulsado por las ingentes necesidades de su Orden.

Los religiosos que contaron con artistas laicos calificados, muchos de ellos especializados en Europa, se preocuparon por hacer cumplir las pautas establecidas por la Iglesia transmitidas a través de los concilios y recogidas por tratadistas, quienes como Vincencio Carducho (1633), Francisco Pacheco (1649), Antonio Palomino (1797), entre otros, inducían a la "buena práctica del arte" por medio del ejemplo impreso.

Los contratos que encontramos entre artistas y representantes religiosos durante el periodo hispánico, demuestran la estrecha fiscalización que sobre el artista aplicaba la Iglesia. En ocasiones se le obligaba a ceñirse a un proyecto presentado por un fraile, el que previamente era refrendado por la Orden y, frecuentemente, también por las más altas autoridades religiosas y civiles, como en la carta ya citada de mayo de 1600 dirigida al rey por el virrey Velasco. 
Con motivo de la construcción de la espadaña y la torre de la iglesia de Nuestra Señora del Rosario de Lima se presentan dos ejemplos significativos. El 22 de enero de 1632 el maestro de albañilería Antonio Mayordomo se comprometió con fray Gabriel de Zárate, prior del convento dominico a "hacer en el convento de la dicha orden un campanario del modelo, orden y forma que se contiene en la traza que en está razón tiene fecha el hermano fray Juan García, religioso de la dicha orden sin exceder de manera alguna haciendo todo el dicho campanario de cal y ladrillo..." (Ante Juan Valenzuela, f. 175. Archivo General de la Nación - AGN, Lima). El segundo caso lo encontramos en los legajos del notario Gregorio Herrera, firmado el 21 de marzo de 1659. El maestro albañil Francisco Cano Melgarejo se comprometió con el Prior dominico fray Martín Meléndez a "hacer la torre y campanario de dicho convento de la forma y manera que está la planta dispuesto por el padre fray Diego Maroto" (f. 106. Archivo Menestral Harth-Terré). Se comprometía asimismo a consultarle todos los detalles de la construcción. Queda evidenciada la estrecha colaboración entre el artista y su contratante religioso.

Naturalmente que en este particular se hace indispensable una especial mención. Diego Maroto, religioso dominico, era limeño nacido en 1619. Realizó varias obras en Lima y en otras ciudades del $V$ irreinato a solicitud de las autoridades civiles $\mathrm{Y}$ religiosas que reconocían su sabiduría épéste aspecto.lLlegó asira sèr Maestro Mayor de la Catedral de Lima y Prior Provincial de su Orden a la que de este modo sirvió, como religioso y como artista. Diego Maroto, siendo "criollo" alcanzó altas dignidades que constituyen un ejemplo para el estudio de la organización social del periodo hispánico. Su capacidad profesional fue indiscutible razón para supervisar construcciones, con mayor razón las de sus propios proyectos.

En otra forma de relación contractual, al arquitecto le eran entregados los diseños detallados de la obra. En caso le perteneciera la traza, ésta debía pasar previamente por la revisión y aprobación de los contratantes. No era factible la libre ejecución salvo, naturalmente, que la fama del contratado y su poder de persuasión allanaran el trámite. Sin embargo una vez cerrado el contrato ambas partes debían cumplirlo estrictamente. El arquitecto se comprometía a respetar sus 
estipulaciones y responsabilizarse de la calidad del producto terminado a satisfacción del contratante y de los veedores, quienes emitían sus informes a solicitud de parte o por disposiciones expresas. Incumplir un contrato podía significar la separación del gremio respectivo, el pago de multas de diversa índole y en ocasiones la pérdida de licencia de trabajo o el exilio.

En técnicas como la escultura, el artista solía recibir el encargo de producir, exactamente o con ligeras modificaciones, una obra de otro artista. Es lo que Harth-Terré denominó "mimetismo", y que vemos también como exigencia para otras artes.

Con el convento de Santo Domingo, el escultor Alvaro Bautista de Guevara se obligó a "hacer un santo de madera de cedro por barnizar y pintar de la advocación de San Jacinto, de la hechura y cuerpo de Santo Domingo que está en la iglesia y convento del dicho santo de esta ciudad de aquella misma hechura y modelo..." (Ante Francisco Alexandre, f. 45-18. III. 1596. AGN- Lima). Esta modalidad de convenio era común tanto a contratantes laicos como religiosos. La costumbre aparentemente Nlevaba implícita la finalidad de evitar desviaciones en el resultado ûltimo de la obra.

De la misma manera se presenta el caso del azulejero Eugenio Díaz, cuando éste se comprometió a sôlar êt corơ alto del convento de Santo Domingo "dé Jadrilbucoladol y entreverado con azulejos estrellados del tamaño y modelo que tienen comunicado con un lazo y medio al mismo modo y tamaño del que está en la capilla real de esta corte y asimismo se obliga a hacer dos por guardas en la forma que tienen tratado". (Ante López Varela, fs. 73.29.I.1651. AGN - Lima).

Otro contrato similar firmó Diego Guillén el 16 de mayo de 1613 con los mayordomos de la capilla de la Hermandad de los Hermanos 24, Cofradía de la Santa Veracruz, en Lima. En este caso Guillén construiría una portada para la mencionada cofradía, en ladrillo, "como la portada de la capilla de Nuestra Señora de la Soledad". (Ante San Francisco Hernández, f.1026. AGN - Lima). Se repite la situación en el caso de los carpinteros Juan Cáceres y Juan Coronado quienes el 10 de marzo de 1626 aceptaron trabajar unas andas para la cofradía del Santo Nombre de Jesús contra los Juramentos, fundada en el conven114 
to de Santo Domingo. Debían tallarla de la "suerte, forma y manera como están acabadas las andas que hizo Pedro Vásquez, carpintero, para la cofradía de San Roque fundada en esta ciudad en la iglesia del señor San Sebastián..." (Ante B. Torres de la Cámara AGN - Lima).

Si existiera duda al respecto, en cuanto a la tradición que se esconde tras estos convenios, es interesante señalar que no fue producto exclusivo de las "provincias ultramarinas". Mencionaremos un contrato firmado en Sevilla con un escultor de la importancia de Juan Bautista Vásquez, lo que nos llevaría a afirmar que debió ser costumbre extendida en la época. El encargo provino de don Gerónimo de Aliaga, residente en Lima, entonces en España. Encargó una escultura de San Gerónimo "de madera de cedro con crucifijo y león y calabaza del tamaño, forma y hechura y postura de un San Gerónimo que está en la iglesia de San Gerónimo extramuros desta ciudad que no ha de tener más diferencia sino sólo ser el uno de barro y este que tengo que hacer de madera y mas a de tener un tronco de altura de una vara y de grueso de una muñeca dado de verde y con sus gajos del mismo árbol con las cortaduras doradas... e dar pintado y encargado con las pinturas y colores que tiene el dicho San Gerónimo..." (López Martínez, Héctor. Sevilla, 1929, 113. Ref. San Jerónimo Penitente de Pedro Torregiano para el monasterio del mismo nombre después del Museo de La Merced de Sevilta) [12:1.1585]

De la misma manera y en tal sentido, firmaron Luis Ortiz de Vargas "maestro escultor y arquitecto vecino en San Martín como principal pagador y obligado e yo Angelino Medoro pintor de ymaginería vecino en la colación de San Pedro como su fiador otorgamos en favor del dator Jorge de la Peña consultor del Santo Oficio de la Ynquisición que estamos concertados con el susodicho en tal manera que yo Luis Ortiz de Bargas (sic) e de fer obligado a hazer e labrar un rretablo de madera de ensamble y talla en blanco conforme a la traza questa firmada del otro dator el cual se ha de poner en el conbento (sic) de San Alberto desta ciudad de la iglesia de Nuestra Señora del Carmen... en seis meses". (López Martínez, Héctor, 1928, 121).

Otra modalidad se presenta en las oportunidades en que los artistas culminan una obra ya iniciada, ajustándose al diseño de base. Así Martín Alonso de Mesa el 18 de mayo de 1612 se comprometió 
a terminar un retablo en la iglesia de La Merced en Lima. Este había sido dejado inconcluso al morir el padre Juan Bautista Ortega, su iniciador. Debía culminarlo "de la misma manera, acabado y dorado en toda perfección", tal como estaba planteado. (Ante Gómez de Baeza, f. 297. AGN - Lima). Muchos de los informes que emanan de estos documentos permiten una amplia información a la Historia del Arte, sobre todo cuando la obra que sirve de referencia ha desaparecido, así como para conocer el carácter de las transacciones llevadas a cabo en la época.

El Primer Concilio Mexicano, en 1555, estipuló que "ningún pintor español o indio pudiera hacer imágenes o retablos sin ser examinados por los provisores de la Iglesia". (Rojas, Pedro, 1969, III, 146). Entendemos que se refiere a una acción previa a la obra buscando así salvaguardar la pertinencia de la misma. Tomando en consideración que muchos civiles y religiosos llegados al Perú habían tenido estadías en Nueva España, es de esperarse que, aún cuando no encontremos la norma claramente estipulada en el Perú, esta debió aplicarse, por lo menos en Lima. Lo que el Segundo Concilio Provincial Limense (1567) señaló en su capítulo LIII-fue que "la pintura es más ventajosa a los ignorantes que la miran que la escritura a los que leen, juzgamos útil y necesario que las jmágenes de los santos sean visitadas por los ordinarios y rectores de los lugares, y si se encontrasen algunas tan deformes e indecentes, "que se aparten de la verdad de los hechos, y por su deformidad den ocasión de falta de respeto, sean reformadas enseguida...". El Tercer Concilio Limense (1582) refrendaría esta norma, aunque es de advertir que se refiere a obras acabadas, no sujetas a una fiscalización previa, como parece deducirse del caso mexicano. Todas sin embargo, se enmarcan entre las disposiciones del Concilio de Trento (1565) muy específico al respecto, en el que se retoman directivas en base a preocupaciones muy tempranas de la Iglesia Cristiana, (Cláusula 1567: LIII trad. por Rodriguez Demorizi, Emilio. 1966, 117 y Bartra S.J., Enrique, 1982).

Por lo pronto, los artistas eclesiásticos, al contar con aprendices bajo su responsabilidad, debieron ser cuidadosos en las fórmulas que les impartían. Estos, a su vez, se convertirían en seguros agentes divulgadores de aquellas. 
Siendo la Iglesia el más importante promotor de arte en la época, mal podemos imaginar a un artista enfrentando su autoridad, fundamentalmente en un medio que rápidamente se tornó altamente competitivo, obligando a muchos de ellos a emigrar en busca de mercados menos saturados. Es así que encontramos conciertos en que el artista se aviene a respetar especificaciones precisas respecto a la temática y técnica, que incluían calidad en los colores, dimensiones de las obras y materiales a emplear.

Conocemos -como ejemplos relevantes- dos contratos firmados con otros tantos pintores de señalada reputación. El más antiguo de ellos lo firmó Mateo Pérez de Alessio el 14 de noviembre de 1606 para pintar varios lienzos, con indicaciones precisas respecto a la iconografía. Se especificaba que "... todas las cuales fechuras de las dichas imágenes me obligo de las hacer y pintar en lienzos a mi costa y mención y dallas fechas de tres palmas y medio de ancho y largo de cinco palmos y tres dedos que es conforme a la medida que me ha dado el dicho Juan de Vega [el contratante] de pergamino y en ella algunas letras escrito para hacer las cuales le tengo que dar fechas y acabadas al olio con las colores muy finas y bien hechas de todo punto conforme a las obras finas que yo hiciere en mi casa..." (Ante Juan de Cabrera, f. 813v. AGN - Lima - AHT)

El segundo datadel 22 de mayo de 1647 y fue concertado entre "Juan de Balberde passajero que bine de las probincias del Piru y Franscosco de Curbaran, maestro pintor decimos que la abadesa del monasterio de Nuestra Señora de la Encarnación de la ciudad de los Reyes del Piru me entregó 2,000 pesos para hacer los lienzos y pinturas para la iglesia del dicho monasterio los quales habia de mandar hacer luego que se llegase a esta ciudad [Sevilla] a Francosco de Curbaran a saber un lienzo en que se haya pintado un árbol que nace de un árbol que nace de un hombre de la descendencia de Nstra. Sra. con toda su progenie en las ramas cuatro y media varas de alto por dos y media menos cuatro dedos de ancho". (López Martínez, Héctor, 1932 (Of.14.224).

Otros de menor jerarquía debían aceptar propuestas pintorescas como el caso de Luis Fernández, quién concertó con el maestro Pedro de Olmedo en 1638 "Para pintarle cuadros 'a vara cuadrada', por 8 
reales". (Ante Santisteban, f.38. AGN - Lima). Este tipo de contratos aparecen frecuentemente mencionados en el virreinato.

Quedaba poco margen a la libre especulación, según debemos deducir. Pero no debe sorprendernos este procedimiento en las colonias, toda vez que en Europa era práctica constante. Allí no fue obstáculo que impidiera el que connotados artistas manifestasen a plenitud su capacidad creativa ante fórmulas coercitivas.

En América esta orientación formaba parte de un programa con una finalidad específica, prioritaria frente a cualquier otra consideración, en condiciones particulares que requerían la aplicación de métodos de eficacia comprobada. Fue parte del compromiso americano y con escasas excepciones la Iglesia logró su cometido cabalmente. Queda por indagar la participación del artista en el empeño.

$\mathrm{El}$ arte colonial -lejos de sef producto exclusivamente de estas limitaciones- demuestra sư calidad creativa. Este será mucho más evidente en la medida que las indagaciones en el área aparten definitivamente el prejuicio de considerarlo un arte subsidiario y consecuente, aspecto por otra parte epidérmico que no compromete los contenidos ni las formulaciones intrínsecas.

\section{Biblioteca de Letras}

OBRAS CITADAS

«Jorge Puccinelli Converso»

Arragaray, Lucas

1920 La Iglesia en América y la dominación española. Buenos Aires.

BARTRA, S.J., Enrique

1982 Tercer Concilio Limense (1582-1583). Lima, Facultad de Teología Pontificia y Civil.

Cieza de Leon, Pedro de

1550 (1962) La crónica del Perú. Primera Parte. Madrid, Espasa Calpe.

Сово, Bernabé

1639 (1956) Historia de la fundación de Lima. Madrid, B.A.E. 
Lisson Chavez, Emilio

1946 La Iglesia de España en el Perú. Sevilla.

LizarRaga, O.P. Reginaldo

(1603-1609) (1968) Descripción breve de toda la provincia del Perú, Tucumán, Río de la Plata y Chile (1603-1609), Madrid, B.A.E.

LOCKHART, James

1982 El mundo hispanoperuano 1532-1560. México, F.C.E.

LOPEZ MARTINEZ, Héctor

1928 Arquitectos, escultores pintores vecinos en Sevilla. Sevilla.

1929 Desde Jerónimo Hernández hasta Martínez Montañés. Sevilla.

1932 Desde Martínez Montañes hasta Pedro Roldán. Sevilla.

Rodriguez Demorizı, Emilio

1966 España y los comienzos de la pintura y escultura en América. Madrid.

Rojas, Pedro

1969 Historia general del arte mexicanb.México, Ed. Hermes.

Xerez, Francisco de "Jorge Puccinelli Converso"

[1534] 1968 Verdadera relación de la conquista del Perú y la provincia del Cuzco llamada Nueva Castilla. Lima, E.T.A.

- Archivo General de la Nación. lima (AGN)

- Archivo Particular Emilio Harth-Terre (AHT) 